\title{
Next-Generation Technology
}

National Cancer Institute

\section{Source}

National Cancer Institute. Next-Generation Technology. NCI Thesaurus. Code C99491.

The next improvement of a device, procedure, technique, or service that provides a significant improvement in the state of the art. 